\title{
$\mathrm{R} \mathrm{C} \& \mathrm{C}$
}

REVISTA DE CONTABILIDADE E CONTROLADORIA

\author{
UMA ANÁLISE DAS PRÁTICAS DE EVIDENCIAÇÃO \\ CONTÁBIL SOB A ÓTICA DE GRACILIANO RAMOS NOS \\ ANOS DE 1928 E 1929
}

\section{ANALYSIS OF THE PRACTICE OF THE PERSPECTIVE ACCOUNTING DISCLOSURE GRACILIANO RAMOS IN THE YEARS 1928 AND 1929}

Recebido em 27.07.2010| Aceito em 14.08.2010 | 2a versão aceita em 20.08.2010|

Nota: este artigo foi aceito pelos Editores Romualdo Douglas Colauto e Ademir Clemente e passou por um avaliação double blind review

\section{VERA LÚCIA CRUZ}

Mestranda da Universidade Federal de Pernambuco | Av. dos Funcionários, s/n | Cidade Universitária | 50740-580 - Recife, PE - Brasil | E-mail: veralc22@hotmail.com |

\section{JORGE EXPEDITO DE GUSMÃO LOPES}

PhD pela Universidade Federal de Pernambuco - UFPE | Av. dos Funcionários, s/n | Cidade Universitária | 50740-580 - Recife, PE - Brasil | E-mail: jlopes@ufpe.br |

\section{JOSÉ FRANCISCO RIBEIRO FILHO}

Doutor pela Universidade Federal de Pernambuco- UFPE | Av. dos Economistas, Departamento de Ciências Contábeis, 10. andar sala E26 | CDU, CEP: 50000-000 - Recife, PE - Brasil | E-mail: fracisco.ribeiro@ufpe.br | \section{MARCLEIDE M. MACÊDO PEDERNEIRAS}

Mestre pela Professora da Universidade Federal da Paraíba - UFPB I Campus IV - Litoral Norte | Doutoranda do Programa de Pós-Graduação em Administração - PROPAD - UFPE | E-mail: marcleide@gmail.com

\section{RESUMO}

O presente estudo teve o objetivo de investigar as práticas de evidenciação contábil realizadas por Graciliano Ramos quando foi Prefeito nos anos de 1928 e 1929, analisando suas atividades em relação à literatura atual da accountability e com o Decreto n. 4.536/1922 que organizou o Código de Contabilidade da União. Para realizar a pesquisa usou-se o método dedutivo 
por ser um material documental-bibliográfico. Concluiu-se por meio da análise dos dados obtidos que Graciliano Ramos trabalhou dentro do orçamento, montou seu relatório com o intuito de ser transparente ao usuário da informação, praticou de forma simples e clara, através de notas explicativas, suas prestações de contas para demonstrar como realizou sua administração ao Governador do Estado. No entanto, não foi encontrada nos relatórios a prática das partidas dobradas prevista pelo decreto da época. Seus relatórios de encontro de contas, suas explicações da aplicação de cada despesa e geração de receita, traduzem tudo o que ele realizou em cada ano de sua gestão, além de revelar humor e rigor aos atos praticados por um gerenciador da causa pública.

Palavras-chave: Relatórios, Evidenciação contábil, Prestação de contas.

\begin{abstract}
This study aimed to investigate the practices of accounting disclosure made by Graciliano Ramos when he was mayor in the years 1928 and 1929, examining the activities carried out by Graciliano Ramos current literature regarding the accountability and the Act No 4.536/1922 who organized the Code of Accounting of the Union to conduct the survey used the deductive method was to be a documentary-bibliographic material. It was concluded through the analysis of the data that Graciliano Ramos worked within budget, set up his report with the intention of being transparent to the user's information, he practiced in a simple and clear through their notes and balances held to demonstrate how its administration to the State Governor, however, was not found in the reports the practice of double entry provided by the decree of the season. Your reports of settlement of accounts and explanations of the application of each expenditure and revenue generation, translates everything he accomplished in each year of his administration, in addition to revealing humor and rigor to acts performed by a manager of the public cause.
\end{abstract}

Keywords: Reports, Accounting disclosure, Accountability.

\title{
1 INTRODUÇÃO
}

Os Relatórios apresentados por Graciliano Ramos, enquanto Prefeito da Cidade de Palmeira dos Índios em Alagoas reportam as várias informações e realidades que o mesmo vivenciava na época. Levando-se em consideração ser ele um escritor de prosa e verso, Graciliano ao mesmo tempo em que apresentava suas Demonstrações Financeiras com receitas e despesas confrontadas, explicava cada detalhe das arrecadações e dos gastos realizados em sua gestão. Partindo de um saldo inicial ele começou sua gestão provocando primeiro uma revolução na administração em virtude dos vários prefeitos indiretos existentes na época, "Havia em Palmeira dos Índios inúmeros prefeitos: os cobradores de impostos, o Comandante do Destacamento, os soldados, outros que desejassem administrar" Ramos (1994, p.37). Depois realizou um controle financeiro na aplicação de recursos arrecadados visando à necessidade da comunidade.

Apesar da ocupação que exercia como Prefeito, não perdeu sua veia poética e utilizava seu conhecimento na escrita para explicar os Relatórios remetidos ao Governador de Alagoas Álvaro Paes. Através de algumas passagens do escritor Graciliano Ramos como, por 
exemplo: "Trago a V. Exa. Um resumo dos trabalhos realizados pela Prefeitura de Palmeira dos Índios em 1928. Não foram muitos, que os nossos recursos são exíguos. Assim minguados, entretanto, quase insensíveis ao observador afastado, que desconheça as condições em que o Município se achava muito me custaram". Esta citação mostra a preocupação com o usuário da informação, quando coloca no seu relatório "ao observador afastado".

O objetivo deste estudo foi investigar as práticas de evidenciação contábil adotadas por Graciliano Ramos em sua Gestão pública, analisando suas atividades em relação à literatura atual da accountability e confrontar os relatórios de gestão publicados pelo autor com o Decreto n. 4.536, que organizou o Código de Contabilidade da União, datado de 28 de janeiro de 1922.

Segundo Lopes et al (2006, p.172), a racionalização ou combinação de idéias em sentido interpretativo têm mais valor que a experimentação caso a caso, ou seja, utiliza-se a dedução, raciocínio que caminha do geral para o particular. Deste modo utilizou-se no estudo o método dedutivo. A relevância do estudo está em trazer a História das práticas Contábeis Exercidas por Graciliano Ramos, ao demonstrar toda uma organização na confecção de seus Relatórios, visto sua escassez de recursos e falta de pessoas técnicas no assunto.

Diante dos Relatórios Publicados por Graciliano Ramos, e considerando-se a escassez dos recursos disponíveis para ele elaborar suas demonstrações, a falta de conhecimento teórico e prático sobre contabilidade, a falta de pessoal técnico para Ihe ajudar a preparar os Relatórios, busca-se investigar: de que forma a Informação Contábil era Evidenciada por Graciliano Ramos nos Anos de 1928 e 1929?

Este estudo será limitado aos Relatórios finais da Gestão de Graciliano Ramos enquanto Prefeito da Cidade de Palmeira dos Índios no Estado de Alagoas em 1928 e 1929. Seus Relatórios foram enviados ao então Governador do Estado de Alagoas Álvaro Paes, nos anos posteriores a sua administração em 1929 e 1930 respectivamente.

\section{REVISÃO DE LITERATURA}

\section{I RESUMO DA BIOGRAFIA DE GRACILIANO RAMOS}

Graciliano Ramos nasceu no dia 27 de outubro de 1892, na cidade de Quebrangulo, sertão de Alagoas, filho primogênito dos dezesseis. Viveu sua infância nas cidades de Viçosa, Palmeira dos Índios (AL) e em 1894, sua família muda-se para Buíque (PE), onde teve contato com as primeiras letras.

Em 03 de Novembro de 1926 era nomeado por ato governamental Presidente de uma Junta Escolar onde escreveu o seu relatório, mandou imprimir em folheto, e enviou-o ao diretor da Instituição Pública. O Relatório impressionou de tal forma que acabou sendo indicado para o cargo de Prefeito Municipal de Palmeira dos Índios pelo Partido Democrata. A iniciativa da candidatura partiu dos irmãos Cavalcanti, Otávio e Francisco (este ex-aluno de Graciliano Ramos). Apesar da indicação, ele absteve-se por completo de sua campanha a prefeito, não participando de comícios, demonstrações populares, 
conversas com correligionários, por conseguinte de nenhuma atividade que lhe pudesse render votos, veio a ser eleito, juntamente com o seu vice José Alcides de Morais, com uma igualdade de votos (433), tendo comparecido unicamente no dia 07 de outubro de 1927, a sua seção para votar e desapareceu (SILVEIRA, 1982). Foi empossado em 1928.

Ao escrever o seu primeiro relatório ao Governador Álvaro Paes, "um resumo dos trabalhos realizados pela Prefeitura de Palmeira dos Índios em 1928", o qual foi publicado pela Imprensa Oficial de Alagoas em 1929, a veia poética do escritor se revela ao abordar assuntos rotineiros de uma administração municipal.

Os Relatórios elaborados por Graciliano Ramos, enquanto Prefeito da Cidade de Palmeira dos Índios em Alagoas nos anos de 1928 e 1929, são retratados para se chegar as suas explicações em relação à aplicação da contabilidade utilizada na época, se houve a utilização do Decreto n. 4.536, que organizou o Código de Contabilidade da União, datado de 28 de janeiro de 1922, nos termos e forma consignados no Regulamento Geral de Contabilidade Pública que surgiu.

O Decreto surgiu em conseqüência do fato em que o Brasil em 1914 quis levantar um empréstimo na Inglaterra, teve uma resposta inesperada, que espantou o governo do Marechal Hermes da Fonseca. John Bull queria saber as condições financeiras do País, e para emprestar as libras esterlinas exigia nada mais, nada menos, que uma demonstração da receita e da despesa da União. Posteriormente, depois de outras providências e análises, foi então criada a Contabilidade Central da República, pelo Decreto n. 4.536, que organizou o Código de Contabilidade da União, datado de 28 de janeiro de 1922, nos termos e forma consignados no Regulamento Geral de Contabilidade Pública, expedido com o Decreto n. 15.783, de 08 de novembro de 1922, com a sanção do Presidente Epitácio Pessoa. Assim tínhamos o Decreto que determinava os procedimentos de contabilidade pública a serem utilizados a partir desta data.

Para melhor análise tem-se como Receita pública o recebimento efetuado pela instituição pertencente ao Estado, com a finalidade de ser aplicado em gastos operativos e de administração e Despesa pública como sendo o conjunto de dispêndio do Estado, ou de outra pessoa de direito público, para o funcionamento dos serviços públicos Lima e Castro (2006, p.55 e 58).

Nos anos da publicação dos Relatórios a moeda praticada era o Réis simbolizada por RS e \$\$, essa moeda já circulava no Brasil desde a época da colonização, quando veio a independência, em 1822. O Réis foi mantido como nossa unidade monetária, só mudou em 01 de Novembro de 1942 coma criação do Cruzeiro (Cr\$).

Outro ponto dos Relatórios de Graciliano Ramos nos reporta também a comparação com a Legislação Societária da Inglaterra que desde 1844 exigia que as Demonstrações Contábeis se revistam das características do True and Fair View. Esta exigência reflete a necessidade de que haja uma adequada Fidelidade entre os Registros Internos (físico-operacionais) e as Demonstrações Contábeis. A palavra Verdadeiro tem o significado de ser o contrário de Falso e a palavra Justo tem o significado não só de Lucro adequado, mas também o de que corresponde à aplicação de adequadas Políticas Contábeis e que a Evidenciação (Disclosure) das informações contábeis reflete com adequada Fidelidade as transações e eventos que lhes deram origem. 
Continuando a análise foi verificada nos Relatórios a aplicação da Accountability que é um termo da língua inglesa, sem tradução exata para o português, que remete à obrigação de membros de um órgão administrativo ou representativo de prestar contas a instâncias controladoras ou a seus representados. Outro termo usado numa possível versão portuguesa é responsabilização.

Accountability pode ser entendida como ato de prestar contas. Accountability remete a quem desempenha funções de importância na sociedade deve regularmente explicar o que faz, como faz, por que faz, quanto gasta. Não se trata, portanto, apenas de prestar contas em termos quantitativos, mas de autoavaliar a obra. A obrigação de prestar contas, neste sentido amplo, é tanto maior quanto a função é pública, se trata do desempenho de cargos pagos pelo dinheiro dos contribuintes. Mesmo sendo um termo antigo sua prática ou utilização que se tem conhecimento começou em meados dos anos $80 \mathrm{em}$ países de língua inglesa (COBRARI, 2004). Accountability aproxima-se do conceito da obrigação de prestação de contas dos resultados obtidos em função das responsabilidades que decorrem de uma delegação de poder (autoridade), consequentemente, há a geração de uma responsabilidade, que é de prestar contas de seu desempenho e seus resultados.

Com relação ao que foi citado sobre "A Revolução de 1930, mesmo sem ter constituído um marco na história das idéias, foi um evento que abriu espaço para o debate de projetos políticos, permitindo que pensadores pudessem apresentar propostas capazes de se traduzirem em ação governamental" (OLIVEIRA, 1982, p.15). Para se ter montado os Relatórios precisou-se ter uma trajetória Histórica e Política para compreendê-lo.

Palmeira dos Índios foi governada por um homem de caráter forte, firmeza de conviç̧ão, valores enraizados, totalmente desinteressados de vaidades pessoais, enriquecimento ilícito, benesses do poder e um "balde cheio de outros", o que sem dúvida tornava-o "o prefeito pelo avesso" (SILVEIRA, 1982).

\section{METODOLOGIA}

Utilizando o Livro "RELATÓRIOS" de Graciliano Ramos, organizado por Mário Hélio Gomes de Lima publicado pela Editora Record e o Livro "Vivente das Alagoas" de Graciliano Ramos pela Editora Record, 2007, foi utilizado o método dedutivo com o intuito de extrair da idéia geral o Livro as informações necessárias para chegar ao ponto particular levantado pelo artigo. Segundo Lopes at al (2006, p.172) a racionalização ou combinação de idéias em sentido interpretativo tem mais valor que a experimentação caso a caso, ou seja, utiliza-se a dedução, raciocínio que caminha do geral para o particular. De acordo com Silva (2006, p.35) o método dedutivo transforma enunciados universais em particulares. $O$ ponto de partida é a premissa antecedente, que tem valor universal, e o ponto de chegada é o conseqüente (premissa particular).

\section{APRESENTAÇÃO DOS DADOS}

Os dados coletados são uma reprodução dos relatórios enviados por Graciliano Ramos ao Governador da época Álvaro Paes com intuito de demonstrar o que foi realizado durante o ano de sua gestão à frente da Prefeitura de Palmeira dos Índios. Relatório Extraído do Livro Relatórios de Graciliano Ramos (org. LIMA, 1994, p.47-48). Todos os valores em 
estudo estão em Réis moeda da época.

Quadro 1 - Relatório do ano de 1928

\begin{tabular}{|c|c|c|}
\hline \multicolumn{3}{|c|}{$\begin{array}{l}\text { PREFEITURA MUNICIPAL DE PALMEIRA DOS ÍNDIOS } \\
\text { BALANÇO (Exercício de 1928) }\end{array}$} \\
\hline & RECEITA & DESPESA \\
\hline Licenças para estabelecimento & $9: 265 \$ 000$ & \\
\hline Décima urbana & $4: 914 \$ 040$ & \\
\hline Carnes verdes & $18: 742 \$ 000$ & \\
\hline Pesos e medidas & $4: 250 \$ 000$ & \\
\hline Oficina e artistas & $210 \$ 000$ & \\
\hline Cercas e alicerces & $204 \$ 000$ & \\
\hline Vendedores ambulantes & $410 \$ 000$ & \\
\hline Feiras & $16: 780 \$ 100$ & \\
\hline Veículos & $380 \$ 000$ & \\
\hline Depósitos de inflamáveis & $450 \$ 000$ & \\
\hline Bazares e Botequins em festas & $399 \$ 000$ & \\
\hline Construção e reconstrução & $210 \$ 000$ & \\
\hline Serviço doméstico & $180 \$ 000$ & \\
\hline Torcedores de Cana & $10 \$ 000$ & \\
\hline Vendedores de leite & $20 \$ 000$ & \\
\hline Vendedores de doces & $40 \$ 000$ & \\
\hline Terras do Estado & $6: 191 \$ 100$ & \\
\hline Bilhares & $100 \$ 000$ & \\
\hline Aluguel de medidas & $3: 101 \$ 800$ & \\
\hline Cemitério & $340 \$ 000$ & \\
\hline Taxa sanitária & $282 \$ 000$ & \\
\hline Biqueiras & $316 \$ 600$ & \\
\hline Cartas de chaffeurs & $150 \$ 000$ & \\
\hline Divertimentos públicos & $150 \$ 000$ & \\
\hline Placas para veículos & $120 \$ 000$ & \\
\hline Casas de farinha & $625 \$ 000$ & \\
\hline Compradores de madeira & $500 \$ 000$ & \\
\hline Restituições & $68 \$ 100$ & \\
\hline Eventuais & $615 \$ 050$ & \\
\hline Multas & $1: 825 \$ 500$ & \\
\hline Poder legislativo & & $1: 616 \$ 484$ \\
\hline Administração Municipal & & $11: 457 \$ 497$ \\
\hline Arrecadação de rendas & & $5: 602 \$ 244$ \\
\hline Iluminação pública & & $8: 921 \$ 800$ \\
\hline Obras públicas & & $2: 908 \$ 350$ \\
\hline Limpeza pública e estradas & & $25: 111 \$ 152$ \\
\hline Cemitério & & $189 \$ 000$ \\
\hline Gratificações & & $1: 843 \$ 314$ \\
\hline Filarmônica "16 de Setembro" & & $1: 990 \$ 660$ \\
\hline Eventuais & & $1: 069 \$ 700$ \\
\hline Saldo & $71: 649 \$ 290$ & $10: 939 \$ 089$ \\
\hline Saldo do exercício anterior & & $105 \$ 858$ \\
\hline & & $1: 044 \$ 947$ \\
\hline No Banco Popular Agrícola de Palmeira & & $11: 04 \$ 050$ \\
\hline Em Caixa & & $40 \$ 897$ \\
\hline Palmeira, 3 de Janeiro de & RÇAL JOSÉ OLIV & A-Secretário \\
\hline & Palmeira, $8 \mathrm{~d}$ & neiro de 1929 \\
\hline
\end{tabular}




\subsection{EXPLICAÇÕES DAS RECEITAS E DESPESAS DO ANO DE 1928}

\section{RECEITAS E DESPESAS}

A receita, orçada em 50:000\$000, subiu, apesar de o ano ter sido péssimo, a 71:649\$290, que não foram sempre bem aplicados por dois motivos: porque não me gabo de empregar dinheiro com inteligência e porque fiz despesas que não faria se elas não estivessem determinadas no orçamento.

PODER LEGISLATIVO

Despendi com o poder legislativo 1:616\$484 - pagamento a dois secretários, um que trabalha outro aposentado, telegramas, papel, selos.

\section{ILUMINAÇÃO}

A iluminação da cidade custou 8:921\$800. Se for muito, a culpa não é minha: é de quem fez o contrato com a empresa fornecedora de luz.

\section{OBRAS PÚBLICAS}

Gastei com obras públicas 2:908\$350, que serviram para construir um muro no edifício da Prefeitura, aumentar e pintar o açougue público, arranjar outro açougue para gado miúdo, reparar as ruas esburacadas, desviar as águas que, em épocas de trovoadas, inundavam a cidade, melhorar o curral do matadouro e comprar ferramentas. Adquiri picaretas, pás, enxadas, martelos, marrões, marretas, carros para aterro, aço para brocas, alavancas, etc. Montei uma pequena oficina para consertar os utensílios estragados.

\section{EVENTUAIS}

Houve 1:069\$700 de despesas eventuais: feitio e conserto de medidas, material para aferição, placas. $724 \$ 000$ foi-se para uniformizar as medidas pertencentes ao Município. Os litros aqui tinham mil e quatrocentos gramas.

\section{CEMITÉRIO}

No cemitério enterrei $189 \$ 000$ - pagamento ao coveiro e conservação.

ESCOLA DE MÚSICA

A Filarmônica 16 de Setembro consumiu 1:990\$660 - ordenado de um mestre, aluguel de casa, material, luz.

\section{FUNCIONÁRIOS DA JUSTIÇA E DA POLÍCIA}

Os escrivães do júri, do cível e da polícia, o delegado e os oficiais de justiça levaram $1: 843 \$ 314$.

\section{ADMINISTRAÇÃO}

A administração municipal absorveu 11:457\$497 - vencimentos do Prefeito, de dois secretários (um efetivo, outro aposentado), de dois fiscais, de um servente; impressão de recibos, publicações, assinatura de jornais, livros, objetos necessários à secretaria, telegramas. 


\section{ARRECADAÇÃO}

As despesas com a cobrança dos impostos montaram a 5:602\$244. Foram altas porque os devedores são cabeçudos. Eu disse ao Conselho, em relatório, que aqui os contribuintes pagam ao Município se querem, quando querem e como querem. Chamei um advogado e tenho seis agentes encarregados da arrecadação, muito penosa. O Município é pobre e demasiado grande para a população que tem, reduzida por causa das secas continuadas.

LIMPEZA PÚBLICA - ESTRADAS

No orçamento, limpeza pública e estradas incluíram-se numa só rubrica. Consumiram $25: 111 \$ 152$. Cuidei bastante da limpeza pública. As ruas estão varridas, retirei da cidade o lixo acumulado pelas gerações que por aqui passaram; iniciei monturos imensos, que a Prefeitura não tinha recursos suficientes para remover.

\section{POSTO DE HIGIENE}

Em falta de verbas especial, inseri entre os dispêndios realizados com a limpeza pública os relativos à profilaxia do Município.

VIAÇÃO

Consertei as estradas de Quebragulho, da Porcina, de Olhos d água aos limites de Limoeiro, na direção de Cana Brava. Foram reparos sem grande importância e que apenas menciono para que esta exposição não fique incompleta. Os empreendimentos mais sérios a que me aventurei foram a estrada de Palmeira de Fora e terrapleno da Lagoa.

\section{ESTRADA DE PALMEIRA DE FORA}

Tem oito metros de largura e, para que não ficasse estreita em uns pontos, largas em outros, uma parte dela foi aberta em pedra.

Fiz cortes profundos, aterros consideráveis, valetas e passagens transversais para as águas que descem dos montes. Centro e vinte homens trabalham nela quase cinco meses. Parece-me que é uma estrada razoável. Custou 5:049\$400.

\section{OUTRA ESTRADA}

Como, a fim de não se inutilizar em pouco tempo, a estrada de Palmeira de Fora se destina exclusivamente a pedestres e a automóveis, abri outra paralela ao trânsito de animais.

\section{TERRAPLENO DA LAGOA}

O espaço que separa a cidade do bairro da Lagoa era uma coelheira imensa, um vasto acampamento de tatus, qualquer coisa deste gênero.

\subsection{RELATÓRIO DE 1929}

O Relatório apresentado na seqüência se refere ao ano de 1929 , este relatório foi montado de acordo com as explicações realizadas por Graciliano Ramos de como foi a arrecadação e de que maneira foram realizada as despesas no Relatório enviado ao Governador do Estado, considerando que não foram recuperados alguns Relatórios 
conforme foi citado no Livro Publicado Relatórios: "Haveria algum outro relatório escrito por Graciliano Ramos e ao conhecido, além desse que divulgamos? Sim. Lima (1994, p.12).

Quadro 2 - Relatório do ano de 1929

\begin{tabular}{|c|c|c|}
\hline Receitas do ano 1929 & $94: 824 \$ 985$ & \\
\hline Multas & $2: 100 \$ 000$ & \\
\hline \multicolumn{3}{|l|}{ Poder legislativo } \\
\hline Administração Municipal & & $12: 115 \$ 190$ \\
\hline Arrecadação de rendas & & $7: 034 \$ 558$ \\
\hline Fiscalização & & $3: 518 \$ 000$ \\
\hline Iluminação pública & & 7:800\$000 \\
\hline Higiene & & $8: 454 \$ 190$ \\
\hline Instrução & & $2: 886 \$ 180$ \\
\hline Dívida antiga & & $5: 210 \$ 000$ \\
\hline Viação e Obras públicas & & $5: 380 \$ 640$ \\
\hline Estrada Palmeira a Santa'ana & & $26: 871 \$ 930$ \\
\hline Terrapleno da Lagoa & & $24: 391 \$ 925$ \\
\hline Cemitério & & $243 \$ 000$ \\
\hline Gratificações & & $1: 560 \$ 000$ \\
\hline Saldo & $96: 924 \$ 985$ & $105: 465 \$ 613$ \\
\hline Saldo & & $(8: 540 \$ 628)$ \\
\hline \multirow[t]{2}{*}{ Saldo do exercício anterior } & & $11: 044 \$ 947$ \\
\hline & & $2: 504 \$ 319$ \\
\hline No Banco Popular Agrícola de Palmeira & & $2: 365 \$ 969$ \\
\hline Em caixa & & $138 \$ 350$ \\
\hline Total & & $2: 504 \$ 319$ \\
\hline \multicolumn{3}{|c|}{ Paz e prosperidade. Palmeira, 11 de janeiro de 1930} \\
\hline
\end{tabular}

\subsection{EXPLICAÇÕES DAS RECEITAS E DESPESAS DE 1929}

\section{RECEITA - 96:924\$985}

No orçamento do ano passado houve supressão de várias taxas que existiam em 1928. A receita, entretanto, calculada em 68:850\$000, atingiu 96:924\$985.

Não me resolveria, é claro, a por em prática no segundo ano de administração a equidade que torna o imposto suportável. Adotei-a logo no começo. A receita em 1928 cresceu bastante. $E$, se não chegou à soma agora alcançada, é que me foram indispensáveis alguns meses para corrigir irregularidades muito sérias, prejudiciais à arrecadação.

DESPESA - 105:465\$613

Utilizei parte das sobras existentes no primeiro balanço. 
ADMINISTRAÇÃO - 22:667\$748

Figuram 7:034\$558 despendidos com a cobrança das rendas, 3:518\$000 com a fiscalização e 2:400\$000 pagos a um funcionário aposentado. Tenho seis cobradores, dois fiscais e um secretário. Todos são mal remunerados.

GRATIFICAÇÕES - 1:560\$000

Estão reduzidas.

CEMITÉRIO - 243\$000

Pensei em construir um novo cemitério, pois o que temos dentro em pouco será insuficiente, mas trabalhos a que me aventurei necessários aos vivos, não me permitiram a execução de uma obra, embora útil, prorrogável. Os mortos esperarão mais algum tempo. São os munícipes que não reclamam.

ILUMINAÇÃO - 7:800\$000

A Prefeitura foi intrujada quando, em 1920, aqui se firmou um contrato para o fornecimento de luz. Apesar de ser o negócio referente à claridade, julgo que assinaram aquilo às escuras. É um bluff. Pagamos até a luz que a lua nos dá.

HIGIENE - 8:454\$190

O estado sanitário é bom. O posto de higiene, instalado em 1928, presta serviços consideráveis à população. Cães, porcos e outros bichos incômodos não tornaram a aparecer nas ruas. A cidade está limpa.

INSTRUÇÃO 2:886\$180

Instituíram-se escolas em três aldeias: Serra da Mandioca, Anum e Cana fístula. O Conselho mandou subvencionar uma sociedade aqui fundada por operários, sociedade que se dedica à educação de adultos.

Presumo que esses estabelecimentos são de eficiência contestável. As aspirantes a professoras revelaram, com admirável unanimidade, uma lastimosa ignorância. Escolhidas algumas delas, as escolas entraram a funcionar regularmente, com as outras.

Não creio que os alunos aprendam ali grande coisa. Obterão, contudo, a habilidade preciosa para ler jornais e almanaques, discutir política e decorar sonetos, passatempos acessíveis a quase todos os roceiros.

UMA DÍVIDA ANTIGA - 5:210\$000

Entregaram-me, quando entrei em exercício, $105 \$ 858$ para saldar várias contas, entre elas uma de 5:210\$000, relativa a mais de um semestre que deixaram de pegar à empresa fornecedora de luz.

VIAÇÃO E OBRAS PÚBLICAS - 5:644\$495

Os gastos com viação e outras obras públicas foram excessivos. Lamento, entretanto, não me haver sido possível gastar mais. Infelizmente a nossa pobreza é grande. E ainda ordinariamente alcançava, e economizemos com avareza, muito nos falta realizar. Está visto que me não preocupei com todas as obras existentes. Escolhi as mais urgentes. 


\section{ESTRADA PALMEIRA A SANTA'ANA}

Abandonei as trilhas do caetés e procurei saber o preço duma estrada que fosse ter a Sant'ana do Ipanema. Os peritos responderam que ela custaria ai uns seiscentos mil-réis ou sessenta contos. Decidi optar pela despesa avultada.

\section{TERRAPLENO DA LAGOA}

Este absurdo, este sonho de louco, na opinião de três ou quatro sujeitos que sabem tudo, foi concluído há meses.

SALDO - 2:504\$319

Adicionando-se à receita o saldo existente no balanço passado e subtraindo-se a despesas, temos 2:504\$319.

2:365\$969 estão em caixa e $138 \$ 350$ depositados no Banco Popular e Agrícola de Palmeira.

\section{PRODUÇÃO}

Dos administradores que me procederam uns dedicaram-se a obras urbanas; outros, inimigos de inovações, não se dedicaram a nada. Nenhum creio eu, chegou a trabalhar nos subúrbios.

MULTAS

Arrecadei mais de dois contos de réis de multas. Isto prova que as coisas não vão bem.

\subsection{ANÁLISE DA GESTÃO DE 1928}

No Gráfico 1 pode-se perceber que Graciliano Ramos saiu de um valor irrisório no início de sua administração e o transformou ao longo do ano onze vezes maior que o valor inicial que ele começou a trabalhar. Além do crescimento apresentado do saldo em caixa ele conseguiu aumentar a Receita da Prefeitura que inicialmente foi orçada em 50:000\$000, e chegou a 71:649\$290.

Gráfico 1: Relatório do ano de 1928

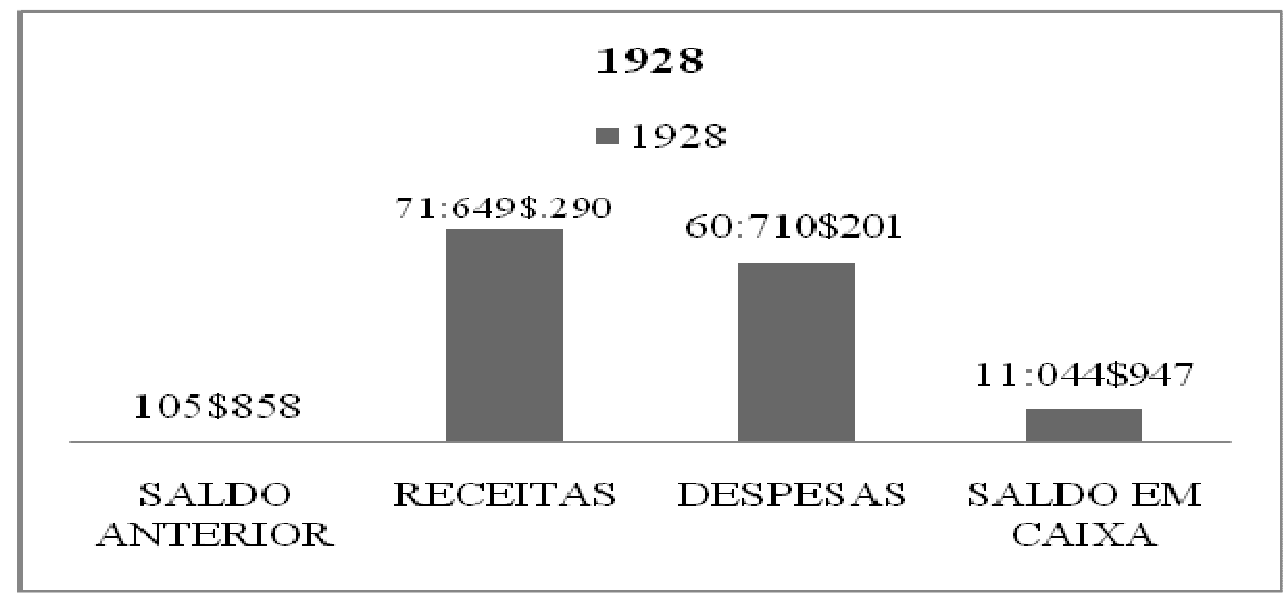


Quando ele fala sobre as Receitas e despesas, refere-se ao orçamento ter superado a previsão de receita. Quando fala sobre as despesas, questiona o orçamento: "Fiz despesas que não faria se elas não estivessem determinadas no orçamento" Ramos (2007, p.194).

$\mathrm{Na}$ época já se trabalhava com o orçamento incluindo a previsão de receitas e despesas para $\mathrm{o}$ ano seguinte. Analisando como essa receita foi aplicada depara-se com os comentários pontuais feitos por Graciliano Ramos em cada uma delas, praticado a prestação de contas de forma simples e esclarecedora para o Governador de como esse dinheiro foi aplicado.

$\mathrm{Na}$ aplicação da receita em iluminação pública tem-se sua explicação do porque o custo foi tão alto se referindo a outras administrações que realizou contrato gigantesco com a fornecedora de energia. $O$ gasto com obras públicas vem descrito item a item: construção do muro do edifício da prefeitura; construção de outro açougue para gado miúdo. A mesma descrição utiliza para as despesas eventuais.

Quando cita o cemitério, utiliza palavra "enterrei", fazendo uma ligação entre cemitério enterro e aplicação do dinheiro. Os gastos com a Escola de música ele agrupa os gastos com ordenado do mestre, aluguel de casa, material e luz. Ao relacionar os gastos com a justiça e polícia ele faz uma relação dizendo que eles "levaram" da prefeitura.

$\mathrm{Na}$ administração como em outras contas citadas tem-se a utilização da conta sintética e ele esclarece os gastos através dos Relatórios explicando que foram vencimentos do Prefeito, os funcionários que ficaram fiscais e serventes, incluem também os gastos com material administrativo, objetos necessários e os famosos telegramas.

Nas despesas de arrecadação aparece citado a contratação de um advogado para ajudar a equipe de arrecadação a cobrar melhor os impostos, porém ele faz questão de ressaltar que o município é pobre apesar de grande para quantidade de pessoas que tem, visto a fuga já na época em virtude das secas contínuas.

Na limpeza pública aparece de novo a veia poética e crítica de Graciliano Ramos, ao proclamar a retirada do lixo deixado por gerações, onde recebeu lamúrias e reclamações, escolheu entre animais e a saúde das pessoas ao citar que mandou matar algumas centenas de cães vagabundos, mostrando assim a preocupação com a saúde da população.

Em seguida mostra seu gasto com a construção do posto de higiene verba essa não prevista, mas realizada com o orçamento da conta da limpeza pública. Ao falar da viação, Graciliano Ramos mostra o humor do poeta que apenas incluiu para que a prestação não ficasse incompleta, daqui ele faz um elo para o que realmente ele construiu que foi a Estrada de Palmeira de Fora.

Quanto à construção da Estrada de Palmeira de Fora, observa-se a riqueza de detalhes que ele citou ao se preocupar em colocar no Relatório as medidas da estrada, a quantidade de homens utilizada, os meses que foram necessários e suas perspectivas de crescimento ao mencionar seu interesse em prolongar até Sant'ana de Ipanema.

Finaliza sua prestação de contas confrontando o que foi arrecadado com os valores gastos, destacando as sobras do ano de 1928. Menciona que abriu uma conta para depositar um dinheiro, mas deixou bem claro que não tem nenhum interesse envolvido em seu procedimento. Mostra transparência e postura em não empregar parentes ou utilizar-se de forma ilícita do dinheiro do povo. 


\section{ANÁLISE DA GESTÃO DE 1929}

Em virtude da melhora do caixa deixado por sua administração em 1928, Graciliano Ramos inicia o ano de 1929 com o propósito de melhorar a situação das pessoas. De posse de um novo saldo em caixa, frutos de sua administração do ano de 1928 , ele mais uma vez supera sua previsão orçamentária, que previu uma receita de 68:850\$000 e atingiu 96:924\$985, e os créditos pelo feito, ele descreveu dizendo que empregou rigores excessivos, conforme representado no Gráfico 2.

Gráfico 2: Relatório do ano de 1929

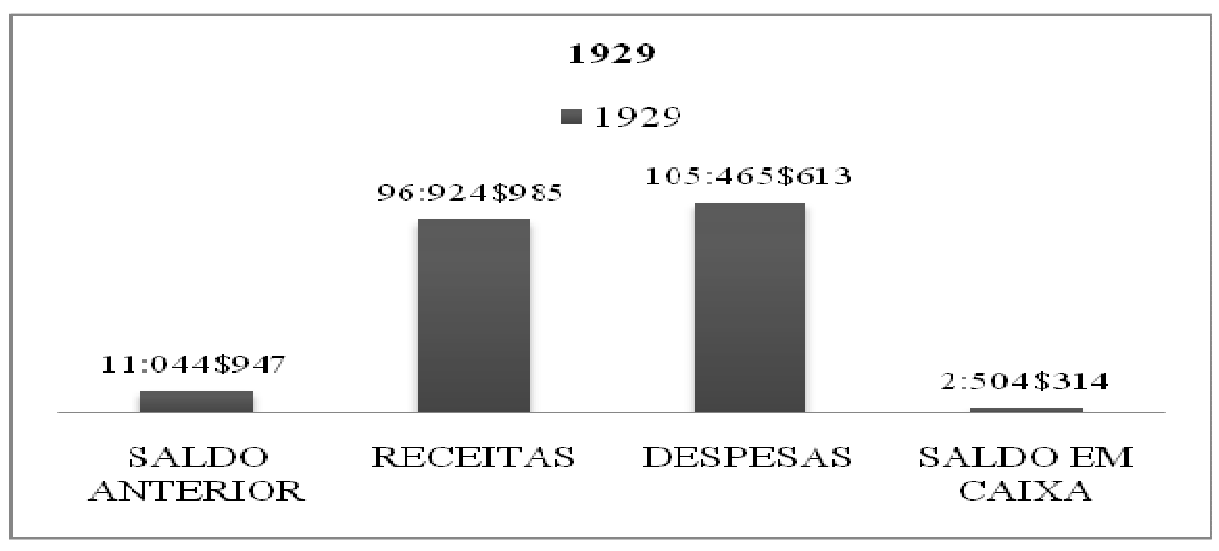

$\mathrm{Na}$ administração foi somado o valor das despesas com a administração Municipal, arrecadação de renda e fiscalização. O valor total da despesa de pessoal da administração representou um aumento de apenas 5,42\% em relação aos salários pagos em 1928, somando os salários pagos em 1929 no valor de 12:115\$190 mais gratificações de 1:560\$000 totalizaram 13:675\$190 em 1929 com pessoal. Nesse momento ele aproveitou para falar dos baixos salários dos funcionários da administração. No mesmo período o Decreto №. 4.536, datado de 28 de janeiro de 1922 em sua tabela contida no artigo 105 mostra que o servente federal na época tinha um salário de 1:600\$000 mais gratificação de $800 \$ 000$ totalizando 2:200\$000.

Partindo para análise das outras despesas tem-se a aplicação no cemitério que representou um aumento em relação ao ano anterior de $22,22 \%$ onde ele falou da sua intenção de construir um novo Cemitério, porém, preferiu investir nos vivos, já que os mortos são munícipes que não reclamam.

$\mathrm{Na}$ iluminação ele mostra toda sua repudia em pagar um contrato existente desde o ano de 1920 e julgou ter sido feito "às escuras", neste ano ele conseguiu reduzi a despesa em $12,57 \%$, e aproveitou para pagar uma dívida antiga com a Prestadora de serviços de energia no valor de 5:210\$000.

Conseguiu acabar com as despesas eventuais ocorridas em 1928, dessa forma todos os gastos em 1929 foram totalmente explorados em suas explicações. Em relação à Higiene ele fala do posto construído em 1928 que trouxe vários benefícios para a população e 
acabou por limpar a cidade de animais de rua, os quais não mais apareceram na cidade, totalizando um gasto de $8: 454 \$ 190$.

Com a Instrução, chegou a gastar 2:886\$180, pois aproveitou as melhores professoras da sociedade fundada por operários com a finalidade de ensinar aos alunos. Ele sabia da incapacidade das professoras capazes para assumirem os cargos, porém, essas poderiam ensinar algum passatempo produtivo e acessível para quase todos os roceiros, como ler jornais, discutir política, decorar sonetos entre outros, não foi citado no Relatório a Filarmônica "16 de Setembro" citada no ano de 1928.

Na Viação e obras públicas o autor totalizou o valor de 56:644\$495, onde incluiu nesta soma o valor gasto com obras públicas $5: 380 \$ 640$, com limpeza pública e estradas $26: 871 \$ 930$ e com terraplenagem da lagoa $24: 391 \$ 925$, gastos citados como excessivo, porém lamentou não ter podido gastar mais, em virtude da pobreza que era muito grande.

Após a análise dos dados ficou evidenciado que Graciliano Ramos se preocupava em atender o que era previsto no orçamento quando ele citou que superou a receita prevista e não realizou algumas despesas em virtude que não estava fixada no orçamento, no entanto, não evidenciado a questão das partidas dobradas citadas pelo Decreto no 4.536 de 28 de Janeiro de 1922, não localizado no material disponível para o estudo. Sem ser um visionário já praticava a accountability que é na sua tradução mais simples o ato de prestação de contas, evidenciado nas explicações de como foi realizado a aplicação dos recursos.

\section{CONSIDERAÇÕES FINAIS}

Após a análise dos dados, entende-se que Graciliano Ramos se preocupava em atender o que era previsto no orçamento, e sem ser um visionário já praticava a accountability que é o ato de prestação de contas que apesar de ser uma prática antiga no mundo só se tem conhecimento no nosso País a partir dos anos 80 . Porém, pelos relatórios encontrados não se pode evidenciar como era realizada a contabilidade em suas partidas dobradas prevista pelo Decreto no 4.536 de 28 de janeiro de 1922, mas, apresentou seu relatório mostrando o confrontado (saldo anterior + receitas - despesas $=$ saldo em caixa).

Num mundo tão moderno com a Tecnologia da informação gerando sistemas que amarrem mais os processos da empresas e dos órgãos públicos para se evitar fraudes, desvios entre outras coisas que se vê diariamente, teve-se a oportunidade de voltar ao passado e descobrir, que, a qualidade da evidenciação dos resultados não está numa Lei ou num sistema de controles avançados. Graciliano Ramos não precisava que existisse uma Lei para executar uma boa prestação de contas, provando que a necessidade de uma boa execução das demonstrações está nas formas mais simples de se comunicar com o usuário da informação, de outro modo, se continuará buscando respostas em coisas impressionantes e se esquecerá apenas de demonstrar o que realmente pode ser útil para o usuário. 


\section{REFERÊNCIAS}

ALBUQUERQUE, João Henrique Medeiros; ANDRADE, Cacilda Soares de; MONTEIRO, Geiziane Braga; RIBEIRO, Juliana Cândida. Um estudo sob a óptica da teoria do agenciamento sobre a accountability e a Relação Estado. Anais...Congresso da USP, 2007.

Enciclopédia Livre. Definição de Accountability. Disponível em: <http://pt.wikipedia.org/wiki/Accountability>. Acesso em: 26 de julho de 2009.

FARIA, Camila Conceição Modernismo.Disponível em:

http://www.infoescola.com.br/literatura/modernismo. Acesso em: 30 de maio de 2009.

História das Licitações. Decreto 04.536 de 28 de Janeiro de 1922. Disponível em: www.conlicitacao.com.br/historia/decreto4536.php, Acesso em: 23 de junho de 2009.

LOPES, Jorge; PEDERNEIRAS, Marcleide; DANTAS, Felipe; MULATINHO, Caio; MONRANT, Dimmitre - O fazer do trabalho científico em Ciências Sociais Aplicadas. Recife: Universitária, 2006.

LIMA, Diana Vaz de; CASTRO, Róbison Gonçalves de; Contabilidade pública. 2. ed. São Paulo: Atlas, 2006.

LOPES, Jorge; RIBEIRO FILHO, José Francisco; PEDERNEIRAS, Marcleide; Educação contábil: tópicos de ensino e pesquisa. São Paulo: Atlas, 2008.

PINHO, Antônio José de. Regionalismo o Modernismo: Uma Breve Análise Histórica da Dependência Intelectual na Literatura Brasileira - MAFUÁ - Revista de Literatura em Meio

Digital. Disponível em: <www.mafua.ufsc.br/numero10/ensaios/pinho.htm>Acesso em: 23 de junho de 2009.

RAMOS, Graciliano; Viventes das Alagoas. 19. ed.. Rio de Janeiro: Record, 2007.

RAMOS, Graciliano; Relatórios (organização Mário Hélio Gomes de Lima). Rio de Janeiro: Record, 1994.

SILVA, Antônio Carlos Ribeiro da: Metodologia da pesquisa aplicada à contabilidade 2. ed. São Paulo: Atlas, 2006.

SILVEIRA, Paulo de Castro. Graciliano Ramos, Nascimento, vida, glória e morte.

Fundação Teatro Deodoro FUNTED, Maceió,AL, 1982. p.210.

Presidência da República Casa Civil. Subchefia para Assuntos Jurídicos.Disponível em: www.planalto.gov.br/ccivil_03/decreto/1910-1929/D15783.htm.Acesso: 30/05/2009.

Releitura - Resumo Biográfico e Bibliográfico. Disponível em: http://www.releituras.com/graciramos_bio.asp. Acesso: 30/05/2009.

Revista eletrônica do Tribunal de Contas do Estado de Minas Gerais. Disponível em: http://www.tce.mg.gov.br. Acesso em: 25 julho de 2009. 